\title{
U.S. Malpractice in Internal Medicine: Closed Claim Cases as Tools for Identification, Teaching and Prevention
}

\author{
${ }^{1}$ Kimberly Ku, ${ }^{2}$ Theresa Vettese and ${ }^{2}$ Diane Levine \\ ${ }^{1}$ Indiana University School of Medicine, Indianapolis, USA \\ ${ }^{2}$ Department of Internal Medicine, Wayne State University School of Medicine, Detroit, USA
}

Received 2013-08-14, Revised 2013-09-01; Accepted 2013-09-02

\begin{abstract}
Medical malpractice litigation as a system in the U.S. serves multiple goals, including the promotion of safer medicine and the compensation of wrongfully injured patients. However, these aims are often at odds with systems-oriented strategies needed to promote patient safety. Additionally, there is widespread doubt of the actual fairness and efficiency of malpractice litigation. Regardless of the details surrounding major tort reform, to prevent malpractice claims physicians need to practice greater awareness of the evidencebased factors that place them at higher risk for a malpractice claim. Closed claims can be used as positive teaching tools that allow physicians to recognize for themselves important preventive strategies in the area of litigation. Internal medicine may not traditionally be thought of as a comparatively high-risk specialty field. In reality, however, an analysis of physicians facing a malpractice claim annually across all specialties shows that the field of internal medicine achieved greater proportions compared to specialty fields that are more often times considered higher-risk, such as emergency medicine and anesthesiology. This article aims to help the internal medicine physician in (1) analyzing the most frequent clinical events that have led to malpractice claims by using a few showcase examples and (2) introducing how these examples of closed claim cases can serve as a learning resource to reduce medical errors that most commonly lead to litigation and thus harms to both patient and provider.
\end{abstract}

Keywords: Medical Malpractice Litigation, Closed Claim Cases, Risk Management Strategies, Medical Errors, Patient Safety

\section{INTRODUCTION}

In the landmark report by the Institute of Medicine in 1999, To Err is Human, it was estimated that the total cost of medical error was 17 to 29 billion dollars per annum (Kohn et al., 2000), with between 44,000 to 98,000 preventable deaths resulting from medical errors (Oyebode, 2013). In this context medical malpractice litigation is a complex issue. The goals of promoting safer medicine and compensating wrongfully injured patients are theoretically logical, yet punitive. An individualistic approach to tort law is often obstructive to the non-punitive, systems-oriented strategies needed to promote patient safety (Studdert et al., 2004). Additionally, there is widespread doubt of the actual fairness and efficiency of malpractice litigation. Nonerror claims are more likely to go to trial and to result in compensation compared to error claims (Studdert et al., 2006). Precise measurement of malpractice system performance is difficult to characterize and hence remains a problem largely unsolved. Major tort reform is needed but there are a variety of reform options with no single option acceptable to all (Kachalia and Mello, 2011; Hermer and Brody, 2010). It is unclear if and when tort reform will happen. Thus, for physicians to prevent malpractice claims, greater awareness of the

Corresponding Author: Kimberly Ku, Indiana University School of Medicine, Indianapolis, USA 
evidence-based factors that place them at higher risk for a malpractice claim is needed (Nepps, 2008).

Although often representative of emotionally charged circumstances, closed claims can be used as positive teaching tools that allow physicians to recognize important prevention points. For instance, Harvard Risk Management Foundation has been developing closed claim abstracts for use in grand rounds or Continuing Medical Education (CME) programs (Martin, 1998).

Internal medicine may not traditionally be thought of as a comparatively high-risk specialty field, but roughly $55 \%$ of physicians in internal medicine and its subspecialties have been projected to face a malpractice claim by the age of 45 years and $89 \%$ by the age of 65 years (Jena et al., 2012; Kane, 2013). In fact, in an analysis of physicians facing a malpractice claim annually across all specialties, the field of internal medicine achieved greater proportions compared to specialty fields that are more often times considered higher-risk, such as emergency medicine and anesthesiology (Jena et al., 2011).

The aim of this article is to aid the internal medicine physician in (1) analyzing the most frequent clinical events that have led to malpractice claims by using a few showcase examples and (2) introducing how these examples of closed claim cases can serve as a learning resource to reduce medical errors that most commonly lead to litigation and thus harms to both patient and provider.

\section{ANALYSIS OF INTERNAL MEDICINE MALPRACTICE CLAIMS}

Troxel et al. (2010) reviewed 369 consecutive closed internal medicine claims from 2000-2007 to identify events that place internists at risk for a malpractice claim. Analysis of claims showed the following: Most allegations were related to (1) diagnosis $(58 \%)$, followed by (2) those related to medical treatment (23\%), (3) medication-specific management $(9.5 \%)$, (4) ordering errors $(2.2 \%)$, (5) patient monitoring $(1.6 \%)$ and $5.7 \%$ were considered miscellaneous.

The same set of claims data was further reviewed with special focus on patient safety/risk management issues, in which 659 were found and categorized as follows: (1) patient assessment (29\%), (2) selection and management of therapy $(11 \%)$, (3) communication with patient/family (11\%), (4) patient factors (10\%), (5) communication among providers (9), (6) patient monitoring (7\%), (7) failure/delay in obtaining consult $/$ referral $(6 \%)$ and $8 \%$ considered other. We refer the reader to the review article by Troxel et al. (2010) for any further clarification regarding each category.
We will subdivide these most common claims categories into focused events and we will draw upon only four closed claims in order to offer specific examples from which to learn key preventive strategies and concepts.

\subsection{Diagnosis-Related Claims}

The $58 \%$ of claims alleging diagnosis-related errors consist of those resulting from failure to make the correct diagnosis (79\%) and those from diagnostic delay (21\%). Cardiovascular disorders were the most common of the claims alleging failure to diagnose $(29 \%)$. For delay in diagnosis, the most common claims resulted from neoplasms (40\%) (Troxel et al., 2010) (Fig. 1).

In terms of mechanisms of diagnostic errors, cognitive issues predominate either alone or in association with system failures (Nendaz and Perrier, 2012; Saber et al., 2013). The majority of cognitive errors are not related to knowledge deficiency but rather to flaws in data collection, data integration and data verification that may lead to premature diagnostic closure. Cognitive psychology, although an important consideration to note, is beyond the scope of this article. For a more detailed discussion, we refer the reader to the 2012 review article by Nendaz and Perrier (2012).

\subsection{Failure to Diagnose Cardiovascular Disorders: A Closed Claim Case (TMLT, 2010)}

\subsubsection{Presentation}

A 51 year-old man came to the Emergency Department (ED) of a regional medical center at 2:55 p.m. on Thursday. The patient had previously been seen at his employer's health clinic for complaints of mild pains in his chest, right and left arms and thigh. Before that visit, the patient had played one hour of tennis, which he did daily. His employer's clinic called his Primary Care Physician (PCP) who instructed him to go to the ED immediately.

\subsection{Physician Action}

The triage nurse at the ED reported that the patient was complaining of chest tightness since 10 a.m. His initial vital signs were: Blood pressure, 151/101 mm Hg; pulse, 106 beats per minute (bpm); respirations, 22 . He was placed on a monitor and pulse oximeter and was noted to be in no acute distress. An emergency medicine physician examined the patient at 3:25 p.m. He noted the patient was in mild distress, but was otherwise asymptomatic. The patient denied the term "chest tightness," but rather complained of "chest sensation". 


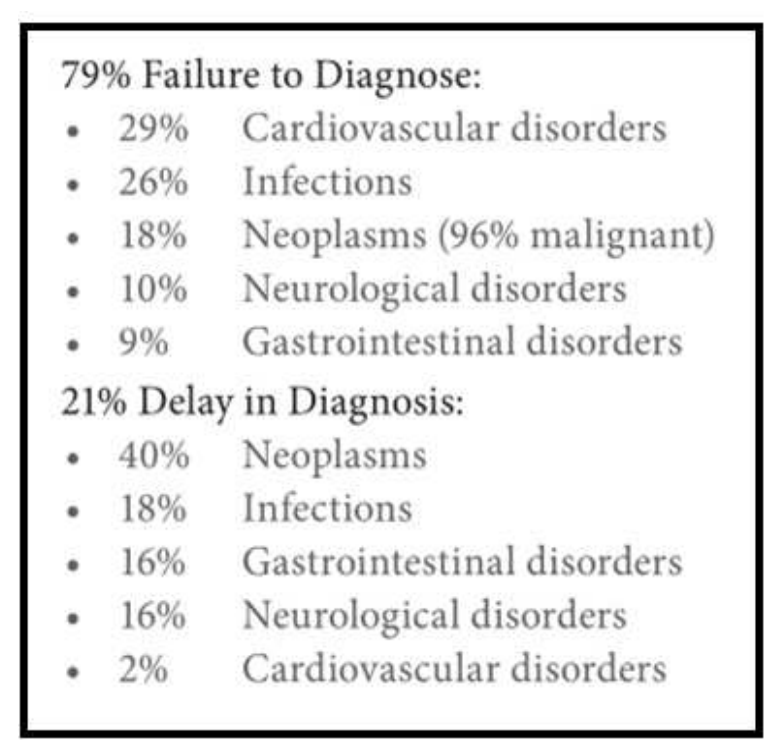

Fig. 1. Diagnosis-related allegations (Troxel et al., 2010) Reprinted with permission, (C2013 The Doctors Company (www.thedoctors.com)

He told the physician his symptoms had started the day before and that he had a physical completed by his primary care physician one month earlier. He took no medications, had no prior surgeries and borderline high blood pressure. He did not smoke, but drank beer.

The physician completed a thorough physical exam and the results were normal. He ordered a monitor, chest $\mathrm{x}$-ray, pulse oximeter, oxygen, a heplock and lab work including a $\mathrm{CBC}, \mathrm{UA}, \mathrm{Chem} 7$, cardiac enzymes and PT/PTT. He ordered two baby aspirin to be given during the work-up. The physician's recollection is that the patient's chest sensation was not continuing at the time he saw him. The patient's lab results and chest x-ray were within normal limits. An EKG revealed a normal sinus rhythm with nonspecific T-wave changes laterally.

Because the patient did not have chest pain during the ED visit and his symptoms were reported to the physician as having started more than $24 \mathrm{~h}$ earlier with no enzyme elevation, the physician did not recommend admission. At 5:15 p.m., the emergency physician called the patient's PCP to schedule a follow-up appointment. Though the details of the conversation were not documented, an appointment was scheduled for Friday morning. The patient was given two baby aspirins and discharged at 5:30 p.m. He was instructed to follow up with his PCP, resume a normal diet, take ibuprofen 3 times a day, to rest and to return to the ED if symptoms persisted or worsened.
The patient did not keep the Friday follow-up appointment. He died two days after the ED visit (Saturday) while playing basketball with his son. The autopsy report listed the cause of death as "a cardiac arrhythmia due to myocardial ischemia due to severe coronary atherosclerosis (heart attack)".

\subsection{Allegations}

Lawsuits were filed against the emergency medicine physician due to alleged negligence for not immediately admitting the patient to the hospital; and the patient's primary care physician due to issues surrounding scheduling of the patient's follow-up appointment.

\subsection{Legal Implications}

According to expert testimony, both physicians fell below the standard of care. An emergency medicine expert stated that the patient should have been admitted for serial EKGs and cardiac enzymes to rule out acute coronary syndrome, as well as being scheduled a prompt stress test. Had the patient been admitted, he would still be alive, according to the expert. The PCP expert claimed the standard of care was breached when the patient's appointment was rescheduled by the physician's office staff. He stated that if the patient had been seen as scheduled, then likely investigation, treatment, referral, or advice could have been given that would have prevented his death.

Defense consultants noted that an appropriate cardiac work-up was completed in the ED, which showed that the patient was not having a myocardial infarction at the time of the ED visit. Further, the patient was appropriately referred to his PCP for follow up the next day but he failed to keep that appointment. The main weakness of the case remained, however, that the physician did not admit the patient or order repeat EKGs or cardiac enzyme tests. The emergency physician also did not solicit the history of playing tennis when the pain started; history of high cholesterol; history of having been seen at his employer's health clinic that day; and history of a prior cardiac work-up by a cardiologist. With this information, the physician would have admitted him as an urgent, but stable patient.

This case was complicated by conflicting testimony from the PCP and the emergency physician about the scheduling of the follow-up appointment and the conversation between these two physicians was not documented. The patient's wife and the PCP also gave conflicting accounts regarding the rescheduled appointment. The PCP's medical assistant testified that when the patient called, he stated he was feeling better 
and did not want to come in Friday. She told him that was fine and to come in on Monday without checking with the physician first. Documentation of this conversation on Friday was not completed until Monday.

Patient accountability was an issue in this case, as the patient did not follow discharge instructions to "rest" by playing basketball, leading to his collapse and death. Additionally, the patient failed to follow up with his primary care physician as instructed.

\subsection{Disposition}

This case was settled on behalf of the emergency physician and the PCP.

\subsection{Solutions and Preventive Strategies}

This was a case of misdiagnosis on the part of the emergency physician likely due to omitted information from the patient's history and hence inadequate follow up management.

Systems errors ensued upon the involvement of the PCP and office staff. Developing guidelines describing staff responsibility and decision-making will prevent staff from exceeding their authority and rendering advice without your knowledge.

Strict protocols for documentation in the medical record apply to physicians and staff. The conversation between the emergency physician and PCP was not documented. Secondly, the phone call between the patient and medical assistant was not documented contemporaneously but was written as a late entry that was not identified as such. Patient accountability was a factor but not the sole focus of this claim since, in retrospect, if the patient had been accurately diagnosed and admitted from the ED he might be alive today.

\subsection{Delay in Diagnosis of Neoplasm: A Closed Claim Case (TMLT, 2010)}

\subsubsection{Presentation}

A 59-year-old man with over 40 years smoking history, chronic obstructive pulmonary disease, sleep apnea, chronic bronchitis, emphysema and obesity was seen in the ED for complaints of respiratory problems. A chest $x$-ray noted a "possible $1 \mathrm{~cm}$ pulmonary nodule superimposed over the anterior end of the left 5th rib," which was not present on films seven months earlier. The radiologist recommended a left rib series, which was not done because the patient left against medical advice. This report was faxed to the patient's internal medicine physician.

\subsection{Physician Action}

The internal medicine physician's partner had his nurse call the patient to inform him of the abnormal results of the chest $\mathrm{x}$-ray and to have the patient return to the clinic in the near future. This call was not documented in the record and the practice did not schedule the patient for an appointment.

Two months later, the patient came to the ED and was hospitalized after a serious episode of respiratory distress. The chest X-ray showed "a nodular density over the left anterior 5th rib measuring $2.7 \mathrm{~cm}$," an increase in size from the previous film. This report noted the internal medicine physician as the ordering physician. The report was in the patient's medical record at his practice, despite the internal medicine physician's testimony that he did not see the report.

The patient came to the clinic the following month, was diagnosed with bronchitis and treated by the internal medicine physician. Two months later, the patient was admitted to the hospital by the physician's partner. Differential diagnosis was pneumonia or empyema. Chest x-ray noted "a mass-like infiltrate" now measuring at a further increased $5 \mathrm{~cm}$ in diameter. A repeat film two days later noted, "the previously described nodule or mass was totally obscured by pleural effusion". Four days later, a PA and lateral of the chest again noted the "large left basilar mass and suspected consolidation completely obscured by overlying effusion," and could not be evaluated. Two days later a CT scan of the chest was ordered. The radiologist noted the pulmonary windows showed no discreet mass and suspected the mass-like density adjacent to the heart border on earlier films represented some focal lung consolidation or loculated fluid. Three days later, an empyema of the left chest was drained with x-rays done to confirm chest tube placement. Four days later, after removal of the chest tube, the last film before patient's discharge noted, "moderate opacification remained in the left lung base," but was slightly improved since the previous study. Thirty-four days later, the internal medicine physician ordered a chest x-ray to rule out pneumonia. That report noted an apparent mass-like infiltrate, again seen in the frontal view. The radiologist noted the lack of change of that focal infiltrate raised the possibility of neoplasm and recommended a CT scan, which was done seven days later and revealed a " $4.5 \times 3 \mathrm{~cm}$ mixed density mass seen inferior laterally in the inferior lingular segment of the left upper lobe abutting the pleural surface". The radiologist noted that malignant neoplasm remained a definite consideration. Eleven days later, biopsy of the 
lung tissue was performed and pathology indicated nonsmall cell and squamous cell carcinoma. At last report, approximately seven months after his first presentation to the ED for respiratory problems, the patient remains under the care of an oncologist and has received multiple courses of chemotherapy.

\subsection{Allegations}

A lawsuit was filed against the internal medicine physician for failure to diagnose cancer, refer and treat in a timely manner.

\subsection{Legal Implications}

Causation was difficult to prove due to patient noncompliance. Also physician reviewers had disparate opinions as to whether an earlier diagnosis of seven months would have made a difference in treatment and prognosis. However, negligence can be implied with the lack of timely follow-up to the abnormal chest x-ray seven months prior to diagnosis.

\subsection{Disposition}

This case was settled due to uncertainty of a jury trial given the physician had no practice protocol to review all patient reports.

\subsection{Solutions and Preventive Strategies}

Physician/patient accountability is unequal in health care so physicians should proactively design and implement processes to meet standards. Losing track of a patient who requires continuity of care, particularly in response to any abnormal report, places a physician at risk. Rather than advising the patient to "return to the clinic in the near future," give the patient a scheduled appointment. He/she can be contacted in the event of a missed appointment and this action would then be documented in the medical record. If the patient is not compliant, a "no show" follow-up appointment is advisable.

Timely review and appropriate follow up on all patient reports is an important part of routine practice protocol among staff, as demonstrated in this case of delayed diagnosis. The ordering/referring physician has this responsibility and allowing reports to be filed in the patient's record without review cannot be defended. Physicians are encouraged to document review of reports and ensuing follow up orders. This practice requires special consideration as the use of electronic health records becomes commonplace and the legal standard of care evolves (Mangalmurti et al., 2010).

The medical record should have a designated place for documentation of phone calls both during and after hours. Patient noncompliance needs to be documented. When necessary the physician may terminate the physician/patient relationship. This entails notifying the patient via certified and U.S. mail and placing a copy of the letter in the medical record. The letter should advise the patient to select another physician and offer your availability for medical emergencies for a given time frame (e.g., from 15 to 30 days). Avoid any actions and comments that can be construed as abandonment.

\subsection{Treatment-Related Claims}

The $23 \%$ of claims that alleged negligence related to medical treatment were subdivided into seven categories: The most being (1) improper management and/or treatment $(69 \%)$, then (2) failure to treat $(9 \%),(3)$ delay in treatment or procedure $(6 \%),(4)$ improper performance of a treatment or procedure $(6 \%)$, (5) premature end of treatment $(5 \%), 6)$ wrong or unnecessary treatment or procedure (1\%) and miscellaneous (4\%) (Troxel et al., 2013) (Fig. 2). Note that the $23 \%$ of claims related to improper medical treatment is separate from that of medication-specific management $(9.5 \%)$

\subsection{Improper Medication Management-A Closed Claim Case (TMLT, 2010)}

\subsubsection{Presentation}

A 50-year-old Asian man was referred to a nephrologist for renal insufficiency. The patient had a history of ankylosing spondylitis and scleroderma. He had an elevated serum creatinine, low creatinine clearance, anemia and proteinuria. The patient had previously been prescribed $5 \mathrm{mg}$ of prednisone daily for treatment of his renal disease.

\subsection{Physician Action}

The nephrologist felt there was no evidence of acute sclerodermal crisis to account for the patient's renal failure. He placed the patient on an ACE inhibitor. After 10 weeks, the patient's creatinine failed to improve and proteinuria was still significant. The nephrologist believed the patient had an undefined connective tissue disorder characterized by probable membranous glomerulonephritis renal lesion. He followed the patient for several weeks. In the interim, the patient had seen his rheumatologist, who increased his prednisone to $10 \mathrm{mg}$ daily.

When the nephrologist next saw the patient, he documented that he discussed the possibility that renal replacement therapy would be needed. According to the physician, the patient indicated he did not want to go on dialysis because he was afraid it would impair his ability to work. 


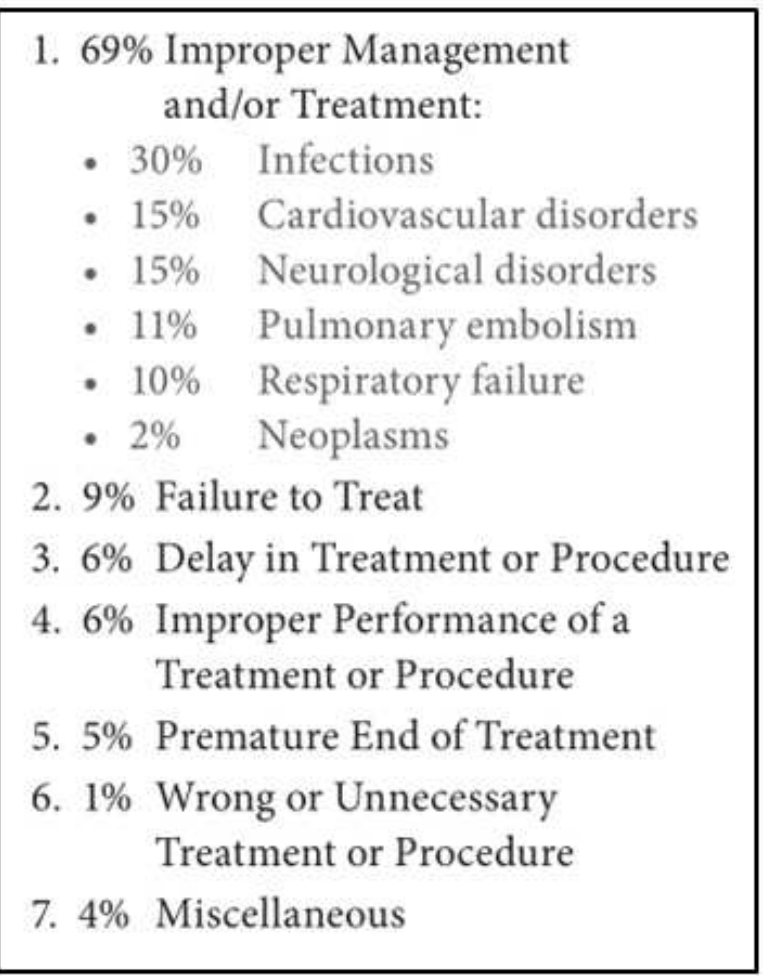

Fig. 2. Medical-treatment related allegations (Troxel et al., 2010) Reprinted with permission. (C2013 The Doctors Company (www.thedoctors.com)

The patient's kidney function continued to deteriorate. During the next visit, the nephrologist decided to place the patient on $120 \mathrm{mg}$ of prednisone every other day to see if renal function would improve. The physician sent an email to his nurse stating, "Kidney function is slightly worse. As a last ditch effort to keep him off dialysis we need to have him take prednisone $120 \mathrm{mg}$ every other day".

The next day, the nurse called in the prescription to the pharmacy for prednisone $120 \mathrm{mg}$ every day and completed the medication summary in the chart to reflect $120 \mathrm{mg}$ daily. Using the practice's computerized records system, the nurse emailed a copy of the prescription back to the nephrologist, which reflected $120 \mathrm{mg}$ daily. When the nephrologist, who had been out of town, returned 10 days later he simply clicked a signature box without opening the email and deleted the prescription from his email list. The pharmacy's computer flagged the prescription because the dosage was too high. The pharmacist called and spoke to the nurse, who confirmed the dosage. The patient's wife also questioned the dosage and was told by the nurse that the dosage was correct.
The nurse later testified that she confirmed the dosage in the computer system by looking at her documentation rather than the actual physician's order.

Nine days after beginning the daily prednisone, the patient came to the clinic for a Procrit injection. He complained to the nurse of tremors, esophageal burning, hiccups, stomach pain and swallowing problems. The nurse emailed the nephrologist, who had just returned to the office and told him of the patient's complaints. The physician never saw this email.

Eight days later, the patient called and spoke to the nephrologist, who was unaware of the prescription error. The patient indicated he was not feeling well and the nephrologist advised him to drop his prednisone back to $10 \mathrm{mg}$ per day. An appointment was scheduled for the next day, during which the patient had extremely low blood pressure, elevated heart rate and was going into shock. The patient was admitted to a nearby hospital where he was diagnosed with severe dehydration, gastrointestinal bleeding and symptoms of sepsis. Despite aggressive treatment from a number of specialists, the patient died two days later. An autopsy did not identify a cause of death. However, chronic gastritis was identified with angio-invasive microorganisms consistent with aspergillosis. Multiple ulcers with prominent necrotic centers were found in the colon with full penetration through the muscular wall with reactive peritonitis. The patient was also found to have interstitial lung fibrosis bilaterally.

\subsection{Allegations}

A lawsuit was filed against the nephrologist, the nurse and practice association for prescribing a high dose of prednisone, failure to properly supervise staff in placing an order of prednisone, failure to monitor patient's progress and failure to give appropriate medical orders to stabilize the patient's deteriorating condition.

\subsection{Legal Implications}

Defense consultants were critical of the prescription error by the nurse and her failure to detect the error when questioned by the pharmacist and the patient's wife. The nurse also did not report the patient's complaint of esophageal burning to a physician.

Defense experts expressed their greatest concern regarding the nephrologist's sign-off of the email prescription. The physician indicated that he did not read the email when he signed off on it.

Credible experts were critical of the physician's decision to initiate steroid therapy at all. However, the defendant's decision to place the patient on alternate-day 
high dose steroids was very well reasoned. Defense experts also agreed with the plaintiff's assertions that daily high dose steroids likely contributed to the patient's death. Though most believed that the patient's underlying systemic sclerosis was the primary cause of his death, steroid use likely left him sufficiently immunocompromised and unable to fight infection secondary to his intestinal perforations. This led to overwhelming sepsis and organ failure.

\subsection{Disposition}

This case settled before trial with the physician's consent.

\subsection{Solutions and Preventive Strategies}

Both the nurse and physician made errors in this patient's health care. The nurse did not respond to the pharmacist's appropriate query regarding the prednisone prescription. The physician also did not open and read all email orders requiring his signature. Electronically signing an order is an affirmation that it is correct. There were several opportunities to correct the prescription error, including asking the patient about the dose he was taking, as well as referring back to the physician's original order for prednisone $120 \mathrm{mg}$ every other day.

\subsection{Communication with Patient/Family-A Closed Claim Case (TMLT, 2010)}

Research on why patients sue physicians has repeatedly shown that basic interpersonal skills, such as listening and showing respect, can be just as important as clinical skills in preventing lawsuits (Vincent et al., 1994; Beckman et al., 1994; Byington and Bender, 2000; Levinson et al., 1997; Huntington and Kuhn, 2003). Such skills can be difficult to practice under current time and economic constraints placed on physicians. The below closed claim case, however, demonstrates how interpersonal skills are indeed vital to serving the patient's best interests.

\subsection{Presentation}

A 35-year-old woman came to a primary care practice clinic on July 31 with complaints of right arm and finger numbness and neck pain. She had a history of lumbar surgery six years ago and lumbar fusion five years ago. The patient also reported that she was seeing a psychiatrist for anxiety, depression and mood swings. She was currently taking paroxetine $40 \mathrm{mg}$ and chlorpromazine $150 \mathrm{mg}$. The patient stated that her neck felt like her back did before the fusion.

\subsection{Physician Action}

A Physician's Assistant (PA) examined the patient and found that she was tender on palpation of the cervical vertebrae and shoulder with a tight trapezius muscle. She was noted to have decreased range of motion of the neck and decreased right arm strength. The initial assessment was neck pain, shoulder pain, neuropathy and muscle weakness to the right arm. She was prescribed a methylprednisolone dose pack, propoxyphene napsylate and acetaminophen for pain and carisoprodol for muscle spasms. The office scheduled an MRI of the cervical spine on August 5.

On August 1, the patient called the office complaining of pain. Another PA, with the approval of the supervising physician, called in a prescription for hydrocodone/paracetamol. The patient did not keep her appointment for the MRI that was scheduled on August 5. On August 6, the patient was prescribed promethazine, carisoprodol and hydrocodone/paracetamol, but PCP A denied the request for dextropopoxyphene. The patient again called and obtained refills for promethazine, carisoprodol and hydrocodone/paracetamol on August 9.

On August 12, the patient called for refillshydrocodone/paracetamol, propoxyphene napsylate and acetaminophen, temazepam and paroxetine were prescribed with the understanding that no more medications would be prescribed until her MRI was completed. Office staff then contacted the patient's psychiatrist to determine what medication he was prescribing for the patient. The psychiatrist did not respond to their call or fill out the medication form. The patient had signed a form that would not allow the psychiatrist to release any information about her care and treatment.

The patient failed to show for the MRI that was scheduled for August 19. When she called on August 23 seeking a refill for propoxyphene napsylate and acetaminophen, PCP B denied the request because the patient had not obtained the MRI.

On August 23, the MRI scan of the cervical spine showed a large right paramedian disc protrusion at C6-7 with a mild impression on the anterolateral aspect of the spinal cord. There was also a large paramedian disc protrusion at $\mathrm{C} 5-6$ producing mild neuroforamenal stenosis and pressing upon the right anterolateral aspect of the cord. The MRI results showed changes that would explain the patient's pain. On August 26, PCP B called the pharmacy to approve another 5-day supply of promethazine, hydrocodone/paracetamol and propoxyphene napsylate and acetaminophen. 
The patient called the office on August 28 stating that her pain medications were not strong enough. PCP B requested that she return to the clinic for a follow-up visit. The patient came that day and complained of neck pain and numbness in the right arm. PCP B performed a complete physical exam. He noted that her right arm was weaker than her left and the right trapezius muscle was tender to palpation. The patient mentioned that propoxyphene napsylate and acetaminophen had not helped her in the past; but oxycodone had provided relief. The physician diagnosed cervical disc disease, hypertension and fatigue. He prescribed $40 \mathrm{mg}$ of oxycodone to be taken twice daily; one propoxyphene napsylate and acetaminophen every six to eight hours; and for her to keep a log of her blood pressure. Additionally, he noted that he would schedule an appointment with the neurosurgeon for September 26. He ordered a follow-up visit in two to three weeks for a blood pressure check.

At this visit, PCP B specifically remembered telling the patient not to take other medication when she took oxycodone. He also remembered telling her to begin by taking only one pill per day though he wrote the prescription for two pills per day. He recalled providing specific patient education about the risks of oxycodone. On September 1, the patient called the clinic complaining of pain. The prescription for propoxyphene napsylate and acetaminophen was refilled to treat the patient's breakthrough pain. The patient's psychiatrist prescribed a 30-day supply of temazepam to the patient on September 2.

The following day, the patient's husband found his wife in the garage passed out and covered in urine. He explained that since he found her at 2 a.m., he thought her condition was a side effect of drowsiness. Neither the patient nor her husband notified any medical providers of this incident. On September 5, the patient was found dead by her children on their return home from school.

The medical examiner found that the cause of death was an accidental mixed-drug overdose from oxycodone and propoxyphene napsylate and acetaminophen. The pathologist believed that the patient's excessive consumption of oxycodone and propoxyphene napsylate and acetaminophen was not accidental, nor a suicide because the patient did not consume all the pills from the bottle or leave a note. The cause of death was also not a homicide or natural, but he was left with accident as the only choice when completing the death certificate. Based on the toxicology results, the patient took at least 8 to 10 oxycodone and at least 6 to 8 propoxyphene napsylate and acetaminophen on the morning of her death.

\subsection{Allegations}

Lawsuits were filed against PCPs A and B, as well as their practice for failure to realize that the patient was a drug abuser and for not taking appropriate steps to place the patient under long-term pain management care. Lawsuits were also filed against the psychiatrist, the pharmacy and pharmacist who filled the patient's prescriptions and the physician's assistant.

\subsection{Legal Implications}

Defense experts fully supported the actions of the PCPs in this case. The patient suffered from physiologic pain brought on by injuries to her cervical and lumbar nerves and her spinal cord. Given clear-cut MRI evidence of a lesion capable of causing severe pain, it was appropriate for the PCPs to rely on what the patient said would relieve her pain. The physicians made a good faith effort to treat the patient and relieve her pain. Thus they did meet the standard of care in trying to manage a difficult situation.

Regarding causation, the defense argued that the patient took a huge dose of medication, well in excess of that prescribed by the defendants. If she had taken the drugs as prescribed, she would not have died. During the investigation of this case, it was discovered that the patient had a history of prescription drug misuse dating back more than five years. Her medical records clearly showed that she would manipulate physicians into giving her pain medication and when they finally refused, she would go to another physician. About one month before the patient came to the defendants' clinic, she was dismissed by a neurosurgeon for lying about medications and abusing her medications. Unfortunately, the PCP defendants did not know about the patient's history because she purposefully failed to disclose her previous three treating physicians. She also told her psychiatrist that he could not disclose anything to other medical professionals.

An expert in pain management argued that the PCP defendants should have diagnosed the patient as an addict and initiated an involuntary commitment. However, he could not explain why involuntary commitment was warranted or point to any evidence that the PCPs should have been aware of her addiction. This expert also stated that the results from the MRI mandated an emergency referral to a neurosurgeon. Defense counsel pointed out that the radiologist who read the study did not describe her condition as an emergency or note spinal cord involvement.

The plaintiff's pharmacology expert testified that his primary concern was not with the prescriptions that were 
given, but with the number of pills that the patient was allowed to receive. He stated that she should not have been permitted to obtain a 30-day supply of oxycodone. This expert agreed that the patient's early refill requests could easily be explained by "misuse" of the medication and not "abuse". He conceded that the PCPs appropriately used the "carrot and stick" approach by denying the patient refills when she did not obtain the MRI and making sure refills were on time and not early. Further, he agreed that the patient's conduct was noncompliant, unreasonable and a component that caused her death.

Another weakness in the plaintiff's case involved the actions of the patient's husband when he found the patient passed out in the garage, but then did not take her to the ED or notify any of her treating physicians. The plaintiff's own expert described this as negligence on the part of the husband and agreed that health care professionals would likely have intervened had this episode been brought to their attention.

\subsection{Disposition}

At the trial the defense attorney made a motion for directed verdict. The judge granted the motion, concluding that the plaintiffs did not meet their burden of proof that malpractice occurred in this case. A directed verdict is an order from the judge that one side or the other wins the case with no need for the jury to decide. Motions for a directed verdict are rarely granted as judges tend to let the jury make the decision.

At the end of trial, defense counsel interviewed jury members, who agreed the patient's death was an unpredictable suicide without any fault of the defendants.

\subsection{Solutions and Preventive Strategies}

Documentation was a weakness in this case, as well as communication necessary to recognize and address the patient's potential for substance abuse. The patient had a clear history of depression, including having medications prescribed by her psychiatrist, yet there was no documentation by PCP A about her depression history or whether she was at risk for intentional overdose. PCP B did not have documentation to support his testimony of having appropriately educated the patient about the dangers of oxycodone. Had the PCPs' clinical interview skills been based on building a partnership, exchanging information and shared decision making, this patient's fragile status may have been recognized. Active listening and empathy may have enabled the physicians to more assertively intervene on her behalf.
In retrospective, the patient's actions could be viewed as "red flags" for drug misuse or abuse. Conversely, these actions could also be justified given her significant pain in accord with objective, diagnostic evidence. The defendants appropriately provided the patient with pain medication to support her until she could see a neurosurgeon. Physicians in similar situations can have patients sign a contract consenting to the pain management therapy as directed by the physician. The agreement is intended to protect the patient's access to appropriate controlled substances and to protect the physician's ability to prescribe for the patient.

\section{CONCLUSION}

Malpractice claims analysis provides valuable information about medical errors, system failures and high-risk clinical events that contribute to adverse patient outcomes. Four examples of the most frequent areas for litigation in the field of internal medicine in the U.S. failure to diagnose acute coronary syndrome, delay in diagnosis of neoplasm, medication management error and communication error-were showcased in this article to highlight the teaching potential of closed claims cases. Particularly, the complex cognitive errors in clinical reasoning have been studied in the attempt to understand diagnosis-related errors (Nendaz and Perrier, 2012; Saber et al., 2013; Croskerry, 2013). However, an allencompassing review of common mistakes leading to litigation in the U.S., with associated close claim examples for each, is beyond the scope of this article.

In suggestion for further closed claims topics for learning, we include the following important errors that any internist should carefully consider during routine practice:

- Failing to listen to patients, spend adequate time with them and communicate empathetically with them

- Maintaining illegible or incomplete documentation

- Failure to establish standards of conduct for office staff

- Being inaccessible to patients

- Failure to order and follow up on indicated tests or delay in ordering such tests

- Failure to refer when appropriate, failure to track referrals and failure to communicate with referring physician

- Inappropriately prescribing medications 
- Improper care of patients during emergency situations

- Failure to obtain informed consent

- Allowing noncompliant patients to take charge

Analysis also provides valuable clinical prevention strategies and patient safety topics that may be appropriate for graduate medical education training, CME during licensure renewal and Maintenance of Certification educational programs (Hermer and Brody, 2010). Certainly the improvement of the quality of training at the pre-graduate, postgraduate and continuous levels, by using evidence-based education, should also be considered (Troxel et al., 2010). While U.S. federal and state governments are vital participants, leaders in medical education, licensure and specialty certification may ensure that all physicians have sufficient awareness to safeguard health care programs, patients and themselves.

\section{ACKNOWLEDGEMENT}

We would like to thank Attorney J. Doug Peters, Associate Professor of Medicine at the Wayne State University School of Medicine, for his time and expertise reviewing this article on behalf of physician education.

\section{REFERENCES}

Beckman, H.B., K.M. Markakis, A.L. Suchman and R.M. Frankel, 1994. The doctor-patient relationship and malpractice. Lessons from plaintiff depositions. Arch. Int. Med., 154: 1365-1370. DOI: 10.1001/archinte.154.12.1365

Byington, M. and A. Bender, 2000. Commentary: Communicating with patients. Harvard Risk Manage. Foundat., 20: 1-5.

Croskerry, P., 2013. From mindless to mindful practicecognitive bias and clinical decision making. New Engl. J. Med., 368: 2445-1448.

Hermer, L.D. and H. Brody, 2010. Defensive medicine, cost containment and reform. J. General Int. Med., 25: 470-473. PMID: 20143176

Huntington, B. and N. Kuhn, 2003. Communication gaffes: A root cause of malpractice claims. Proc. Baylor Univ. Med. Center, 16: 157-161. PMCID: PMC1201002

Jena, A.B., A. Chandra, D. Lakdawalla and S. Seabury, 2012. Outcomes of medical malpractice litigation against US physicians. Arch. Internal Med., 172: 892-894. DOI: 10.1001/archinternmed.2012.1416
Jena, A.B., S. Seabury, D. Lakdawalla and A. Chandra, 2011. Malpractice risk according to physician specialty. New Engl. J. Med., 365: 629-636. DOI: 10.1056/NEJMsa1012370

Kachalia, A. and M. Mello, 2011. New directions in medical liability reform. New Engl. J. Med., 364: 1564-1572. DOI: 10.1056/NEJMhpr1012821

Kane, C., 2013. Policy research perspectives-medical liability claim frequency: A 2007-2008 snapshot of physicians. American Medical Association, Chicago.

Kohn, L.T., J.M. Corrigan and M.S. Donaldson, 2000. To Err is Human: Building a Safer Health System. 1st Edn., National Academies Press, Washington, D.C., ISBN-10: 0309068371, pp: 272.

Levinson, W., D.L. Roter, J.P. Mullooly, V.T. Dull and R.M. Frankel, 1997. Physician-patient communication. The relationship with malpractice claims among primary care physicians and surgeons. J. Am. Med. Assoc., 277: 553-559. PMID: 9032162

Mangalmurti, S.S., L. Murtagh and M.M. Mello, 2010. Medical malpractice liability in the age of electronic health records. New England J. Med., 363: 20602067. DOI: $10.1056 /$ NEJMhle 1005210

Martin, P.B., 1998. Using closed malpractice claims as teaching tools. Harvard Risk Management Foundation, Forum.

Nendaz, M. and A. Perrier, 2012. Diagnostic errors and flaws in clinical reasoning: Mechanisms and prevention in practice. Swiss Med. Weekly, 142: w13706- w13706. PMID: 23135902

Nepps, M.E., 2008. The basics of medical malpractice: A primer on navigating the system. Chest, 134: 10511055. PMID: 18988780

Oyebode, F., 2013. Clinical Errors and medical negligence. Med. Princ. Pract., 22: 323-33. PMID: 23343656

Saber, T.A.S., H. Lee, S.C. Mathews, A. Shore, M.A. Makary and P.J. Pronovost et al., 2013. 25-Year summary of US malpractice claims for diagnostic errors 1986-2010: An analysis from the National Practitioner Data Bank. Brit. Med. J. Q. Saf. DOI: 10.1136/bmjqs-2012-001550

Studdert, D.M., M.M. Mello and T.A. Brennan, 2004. Medical malpractice. New Engl. J. Med., 350: 283292. DOI: $10.1056 /$ NEJMhpr035470 
Studdert, D.M., M.M. Mello, A.A. Gawande, T.K. Gandhi and A. Kachalia et al., 2006. Claims, errors and compensation payments in medical malpractice litigation. New Engl. J. Med., 354: 2024-2033. DOI: 10.1056/NEJMsa054479

TMLT, 2010. 10 things that get physicians sued. Texas Medical Association.
Troxel, D.B., R. Diamond and S. Shepard, 2010. The Doctor's Advocate. The Doctor's Company.

Vincent, C., M. Young and A. Phillips, 1994. Why do people sue doctors? A study of patients and relatives taking legal action. Lancet, 343: 1609-1613. PMID: 7911925 